\title{
TERCEIRO SETOR, RESPONSABILIDADE SOCIAL E VOLUNTARIADO
}

\section{ENTREVISTA COM FÁBIO RIBAS}

\section{The third sector, social responsibility and volunteer work}

\author{
Interview with Fábio Ribas
}

\author{
Por Nanci Garcia Cairo ${ }^{1}$ \\ Karla Losse Mendes²
}

\begin{abstract}
"Mudar o mundo está em nossas mãos" é o lema do Centro de Ação Voluntária de Curitiba. O CAV é uma organização não-governamental que atua como uma ponte entre as pessoas que gostariam de ser voluntárias e as instituições que precisam deste trabalho para defender sua causa. A organização dedica-se a promover o voluntariado, realizando, todas as segundas-feiras, reuniões para encaminhar os interessados às instituições. Após participar da reunião, o candidato pode consultar o banco de dados disponível no local e escolher uma instituição de acordo com os horários que tem disponível e o trabalho que deseja desenvolver. Feita a escolha, o interessado entra diretamente em contato com a organização escolhida e inicia o trabalho voluntário.

O banco de dados do Centro de Ação Voluntária conta com 258 instituições cadastradas para receber voluntários e é possível escolher entre quase duzentas atividades diferentes. As tarefas compreendem desde organizar bazares, acompanhar idosos, cuidar de jardins, realizar leituras para crianças cegas, auxiliar administrativo, informática, costureira, e muitos outras. Esta variedade de atividades comprova que todas as pessoas podem ajudar de alguma forma, pois os horários são bastante flexíveis. Algumas instituições fornecem até oportunidades em que o voluntário não precisa sair de casa para ajudar, ele desenvolve a atividade e depois a remete para a instituição, como é o caso de alguns artesãos.

O CAV foi fundado em 1998 e além de disponibilizar vagas para voluntariado, também disponibiliza seu know-how em gerenciamento de voluntariado dentro das instituições, por meio de cursos e encontros com palestras na área.
\end{abstract}

1 Jornalista e colaboradora da Revista Psicologia Argumento.

2 Estudante do terceiro ano de Jornalismo da UFPR.

Endereço para contato: Rua Francisco Schaffer, 637 - Curitiba/PR CEP: 80.820-200

E-mail: nancigc@terra.com.br 
Nestes últimos seis anos, já passaram pelas reuniões promovidas pelo CAV mais de doze mil voluntários. Somente em 2004, foram cerca de cinco mil voluntários que ofereceram aproximadamente seiscentas mil horas de trabalho para causas sociais em Curitiba e Região Metropolitana.

Desde o início dos anos 90 o número de organizações não governamentais vem se multiplicando a cada ano. Mesmo sem dados oficiais, sabese hoje que o Brasil é um dos países com o maior número de ONGs. O aumento de ações relacionadas à Responsabilidade Social Empresarial e Voluntariado também já é significativo. Para abordar o tema, entrevistamos Fábio Ribas, doutor em Psicologia Social pela Universidade Católica de São Paulo e diretor executivo da Prattein ${ }^{3}$, especializada em desenvolvimento social e educação.

Pergunta: O senhor acredita que o terceiro setor está mudando a cara do Brasil?

Resposta: Nenhum setor isoladamente tem capacidade para mudar a cara do Brasil. Todos os setores (poder público, setor privado, terceiro setor) refletem as tensões e conflitos presentes em nossa realidade e, assim, podem tanto portar valores de mudança quanto fortalecer tendências que reproduzem a injustiça e a desigualdade que marcam o país. Atualmente, vivemos uma era de mudanças e incertezas, na qual a riqueza, o desenvolvimento e a tecnologia coexistem com a violência, a desigualdade e a exclusão social. Nesse cenário, o crescimento do terceiro setor pode ser compreendido como um saudável movimento da cidadania em busca de novos paradigmas de desenvolvimento social. Porém, para que traga efetiva novidade, o emergente terceiro setor não poderá ser apenas um mecanismo de amortecimento dos efeitos da exclusão social, mas precisará estruturar-se para ir além, ajudando a criar condições de emancipação e vida digna para os pobres, promovendo a igualdade de oportunidades e a inclusão social. E isto só será possível se souber atuar em colaboração com os demais setores, evitando perceber-se como segmento privilegiado ou panacéia para a solução de problemas sociais. É claro que a prática colaborativa não exclui a iniciativa de pressionar os demais setores para que atuem com responsabilidade social.
Pergunta: Fala-se muito em voluntariado como exercício pleno da cidadania e não como prática meramente assistencialista. Isso pode ajudar no fortalecimento do terceiro setor?

Resposta: O voluntariado é um fenômeno que pode estar passando por um processo de reconstrução, no qual a antiga filantropia assistencial vai sendo progressivamente substituída por preocupações mais efetivas com a concretização de uma sociedade mais justa. Para os que dizem que a inspiração do voluntariado é sempre assistencialista ou conservadora, vale lembrar a frase de Che Guevara, para quem "o voluntariado é uma escola criadora de consciências". Ocorre que o assistencialismo é algo muito arraigado na cultura brasileira e nas próprias políticas sociais, o que torna sua superação um processo complexo. Para trazer algo realmente novo, o "voluntariado cidadão" precisa articular a assistência indispensável à busca da cidadania emancipatória. Esta seria a grande novidade: a descoberta de que o trabalho voluntário pode ajudar a desenvolver nos pobres competências de compreensão da realidade, auto-sustentação e empreendedorismo. Esse voluntariado será capaz, então, de contribuir para que o terceiro setor se desenvolva como um espaço que pode fortalecer a autonomia das comunidades para resolver seus próprios problemas.

Pergunta: Muitas pessoas criticam o trabalho profissional exercido de forma voluntária, alegando que isso tira oportunidades de emprego. É verdade?

Resposta: Não tenho dados para dizer em que extensão isto estaria ocorrendo. Creio que a substituição de trabalho profissional por trabalho voluntário é típica de entidades sociais marcadamente assistencialistas, que oferecem assistência pobre para quem é pobre. Nessas entidades predomina uma compreensão e uma prática limitadas de voluntariado. O novo tipo de voluntário a que me referi em resposta anterior é alguém que possui competências que agregam valor à instituição ou programa social de que participa, mas que não deve e não pode substituir o trabalho profissional. Esse voluntário traz contribuições específicas e diferenciadas que são importantes para

Prattein - Consultoria em Educação e Desenvolvimento Social. A home-page da consultoria pode ser visitada no seguinte endereço: www.prattein.com.br e o E-mail para contato é: prattein@prattein.com.br Telefones: (11) 3826-7142 / (11) 3661-5118 
o avanço dos programas e geralmente contribui para o desenvolvimento das equipes profissionais. Para substituir o trabalho profissional, esse tipo de voluntariado teria que ser exercido de forma intensiva e permanente, o que o tornaria praticamente inviável. Muitas instituições do terceiro setor que buscam aprimorar seu trabalho compreendem a necessidade de contar com equipes profissionais competentes e adotam programas de gestão de voluntariado que combinam de forma inteligente $\mathrm{e}$ produtiva profissionalismo e voluntariado.

Pergunta: O senhor acha válido que profissionais da psicologia disponibilizem seu saber acadêmico para tarefas voluntárias?

Resposta: Sim. Como qualquer profissional, o psicólogo pode atuar como voluntário de causas ou programas sociais. E como o terceiro setor tem forte preocupação com o desenvolvimento humano, o psicólogo pode trazer uma contribuição decisiva.

Pergunta: Nos Estados Unidos o trabalho voluntário é bastante conhecido por sua forma de atuação prática, como, por exemplo, no caso de empregados de uma empresa que se reúnem num final de semana para pintar a escola do bairro. Esse tipo de ação deveria ser incentivado aqui no Brasil?

Resposta: No Brasil muitas empresas já incentivam o envolvimento de seus empregados em ações sociais voluntárias. Porém, há certa confusão no meio empresarial sobre o significado do voluntariado dos empregados e a melhor forma de incentivá-lo. Algumas empresas criam programas sociais próprios e envolvem seus empregados neles, chamando isto de trabalho voluntário, o que não é correto. Já assessorei empresas que tiveram problemas com mobilizações deste tipo, as quais acabaram sendo vistas pelos empregados como atividades de caráter mais "obrigatório" do que "voluntário". Por outro lado, muitas atividades eminentemente voluntárias de empregados, apoiadas pelas respectivas empresas (ou exercidas sem interferência da empresa), apresentam caráter fragmentário e pontual, não indo além de limites tipicamente assistencialistas. Mas há também experiências mais interessantes e bem estruturadas, nas quais o voluntariado autêntico dos empregados é apoiado de forma conseqüente pelas empresas, criando-se espaço para reflexão e aprimoramento da capacidade de ação dos empre- gados no campo social, bem como programas sociais de empresas destinados ao fortalecimento de comunidades, que utilizam deliberadamente as competências dos empregados como recurso essencial.

Pergunta: Em seu artigo "O conceito de terceiro setor", o senhor diz que as ONGs e entidades assistenciais estão sendo valorizadas hoje como organizações portadoras de valores fundamentais para a sociedade. Que valores são esses e qual o papel que desempenham para o desenvolvimento humano hoje?

Resposta: Refiro-me sobretudo ao potencial dessas organizações para propiciar às pessoas novos tipos de inserção na esfera pública, novas formas de compromisso e participação em questões de interesse comum. A crise da democracia representativa tem levado alguns analistas a propor a necessidade de "democratizar a democracia”. Isto significa, entre outras coisas, a criação de mecanismos de participação pelos quais os cidadãos possam influir mais diretamente na vida pública, para além do voto. As ONGs e entidades sociais permitem esse tipo de participação, especialmente quando alargam seu campo de visão e passam não apenas a assistir pessoas, mas também a propor programas e políticas que devam ser assumidos ou apoiados pelos governos e pela sociedade em geral. As organizações do terceiro setor são portadoras de vários outros valores, entre os quais destaco a capacidade de chegar aonde o Estado muitas vezes está ausente: nos segmentos mais esquecidos da sociedade, nas populações mais vulneráveis que, de outra forma, não teriam suas condições de existência, sua voz e suas capacidades reconhecidas e valorizadas.

Pergunta: $\mathrm{O}$ nível de profissionalização das ONGs ainda não é o adequado. O que tem de ser feito para se resolver isso?

Resposta: A profissionalização das organizações do terceiro setor é um processo que envolve várias dimensões: aprimoramento da qualidade dos programas de atendimento, maior capacidade de buscar parcerias e recursos para a sustentabilidade das ações, aprimoramento da competência de gestão e da capacidade de influir em políticas públicas. A busca de profissionalização pressupõe uma autocrítica dos aspectos restritivos da cultura assistencialista na qual grande parte das entidades sociais foi formada, mas também um 
reconhecimento de qualidades próprias, desenvolvidas no decorrer desta mesma formação, que lhes permitem desempenhar um papel essencial na promoção do desenvolvimento social: vínculos de confiabilidade com comunidades locais, agilidade no atendimento às necessidades dos grupos de baixa renda, aptidão para prestar serviços em escala humana, capacidade para mobilizar o apoio e a participação popular para a implementação de mudanças sociais necessárias. Em tempos de mudança, o contato das organizações do terceiro setor com outras culturas de gestão (tanto do setor empresarial quanto do setor público) pode possibilitar a articulação entre conceitos como técnica e carisma, voluntarismo e profissionalismo, e estimular o desenvolvimento de novos princípios e metodologias de ação social.

Pergunta: Quem está mais atento ao terceiro setor, o poder público ou o empresariado?

Resposta: Há alguns anos as empresas que desenvolviam ações sociais estavam mais atentas ao terceiro setor que o poder público. Faziam doações para ONGs e entidades assistenciais, e acreditavam ser mais importante destinar recursos ao terceiro setor que apoiar projetos sociais governamentais. Nessa fase, as empresas tendiam a desvalorizar o papel do Estado no campo social, o que levou (e ainda leva) muitas analistas a verem aí, a meu ver de forma equivocada, unicamente intenções de privatização do espaço público. Nos últimos anos, os governos passaram a reconhecer o terceiro setor como parceiro de políticas sociais, embora este processo ainda tenha que ser muito aprofundado. Creio que o mais importante é que todos reconheçam que o principal desafio no campo social é o desafio da colaboração: é preciso somar esforços em iniciativas intersetoriais que tenham claros objetivos de construção de comunidades mais justas, menos desiguais e mais auto-sustentadas.

Pergunta: Muitas vezes ouvimos que responsabilidade social é mais uma ferramenta de marketing empresarial. Isso é verdade no Brasil?

Resposta: As empresas que concebem a responsabilidade social como simples marketing social não vão muito longe nessa área. Pois cada vez mais a mídia e os consumidores conscientes estão sabendo distinguir entre propaganda interesseira e compromisso conseqüente no que se refere ao desenvolvimento social. Mais do que ferramenta de marketing, responsabilidade social vem sendo concebida como estratégia de sustentabilidade das empresas. No limite, o que está em jogo é o avanço da consciência de que, na fase do capitalismo que ora se inicia, o lucro precisa ser balizado pelo bem comum.

Pergunta: Qual a relação entre psicologia social e terceiro setor?

Resposta: Creio que a psicologia social, por seu foco nas relações entre os indivíduos, as organizações e a sociedade, tem uma natural vocação para oferecer contribuição teórica e prática relevante ao terceiro setor. Mas percebo que os profissionais da psicologia em geral, independentemente de seu interesse por questões de natureza social, são muito valorizados nas organizações do terceiro setor. Isto ocorre porque estas organizações têm forte vocação de apoio ao ser humano, existem para acolher pessoas e promover seu desenvolvimento, o que naturalmente as aproxima da psicologia.

Pergunta: A seu ver, qual é o segmento mais organizado e com maior poder de transformação hoje no Brasil?

Resposta: Como já disse antes, é preferivel pavimentar os caminhos da colaboração, mais do que identificar um setor que, isoladamente, nos possa conduzir a melhores destinos. Todos os setores têm capacidade e poder de transformação. Importa que estejam imbuídos de intenções democráticas e se disponham a construir uma nação mais justa e equilibrada.

Pergunta: O senhor diria aos estudantes de psicologia de hoje que o terceiro setor é um bom caminho a seguir?

Resposta: Certamente é um bom caminho, que, como qualquer outro, não deve ser idealizado. É preciso tomar cuidado com certo modismo e evitar buscar experiências no terceiro setor apenas como fator de enriquecimento curricular. Como sempre, o que deve ser decisivo é a autêntica vocação pessoal. 